\title{
Definitions of Friendship and their Consequences in Old Age*
}

\author{
SARAH H. MATTHEWS $†$
}

\section{ABSTRACT}

In an attempt to gauge the quality of relationships, definitions of friendship were delineated through inductive analysis of transcripts of guided conversations with 30 men and 30 women aged $60+$ who related their biographies using friendships as a constant referent. Two definitions of friendship were constructed, one' which focuses on 'friends as particular individuals' and another which focuses on 'friends as relationships'. Each is described in turn, followed by a discussion of the consequences of holding one or the other or both in old age. Suggestions for intervention strategies tailored to specific definitions are made.

A review of the social science literature on friendship reveals that most research ignores the quality of respondents' relationships, and focuses instead on more easily quantifiable aspects such as number and proximity of those identified as friends. ${ }^{1}$ Further, when the old have served as respondents, 'Investigators have been more interested in the social condition of the elderly than in the investigation of friendship per se.' ${ }^{2}$ This has been bemoaned by some who have recommended that research be undertaken to fill this gap. ${ }^{3}$ Very few, however, have followed this directive, in part because quality is so difficult to conceptualize.

In an attempt to overcome this, the research reported here focuses on definitions of friendship. Social actors, in identifying their friends,

* Revision of a paper presented at the 34th Annual Scientific Meeting of the Gerontological Society of America/ toth Annual Scientific and Educational Meeting of the Canadian Association on Gerontology, Toronto, Canada, November, 1981 . Research was supported by a grant from the National Institute on Aging (AG 02251-02).

$\dagger$ Department of Sociology, Case Western Reserve University, Cleveland, Ohio, USA 44016. 
employ definitions, usually implicit, to decide whom to include in the category and to compare and to evaluate relationships. A delineation of these definitions, then, may provide insight into the quality of relationships. Moreover, since persons' actions are, at least in part, a function of their definitions of situations, a clearer understanding of opportunities for friendship in old age-or at any age-may be accomplished by attending carefully to these definitions.

The presentation that follows begins with a discussion of definitions of friendship, both explicit and implicit, in the literature in order to show how the focus of this research departs from previous research. The research design and the older adults who informed this research are then described. The two definitions of friendship that emerged from analysis of the data are then presented, followed by a discussion of the consequences in old age of subscribing to one or the other or both definitions.

\section{Definitions of friendship in the social science literature}

Within the social science literature on friendship, there are a number of definitions, some of which are carefully constructed. For example, Brown specifies that it is a relationship that is 'voluntary, mutual, flexible, and terminable; relationships that emphasize equality and reciprocity, and require from each partner an affective involvement in the total personality of the other' 4 . Suzanne Kurth contrasts 'friendly relations' with 'friendship', the essential components of the latter being voluntary interaction, a sense of the uniqueness of the individuals, a high level of intimacy relative to other relationships, and unlimited obligation. ${ }^{5}$ John Reisman defines three types of friendship - associative, reciprocal, and receptive - the distinguishing dimensions of which are commitment and reciprocity. ${ }^{6}$

Regrettably, few of the authors of these carefully delineated statements have conducted empirical research to ascertain the degree to which other social actors would concur. Graham A. Allan suggests one reason that may account for this when he writes, 'It is the actual relationship itself that is the most important factor in deciding whether someone can or cannot be labelled a friend. ${ }^{7}$ Labelling someone a friend, then, is purely subjective. Recognition of this means that the investigation of the meaning of friendship must rely on attending carefully to actors' evaluations of their relationships.

In empirical research, definitions of friendship are sometimes simply imposed without consulting the respondents. ${ }^{8}$ For example, in Lowenthal and Haven's research on the relationship between mental health and 
having a confidant, respondents were asked, 'Is there anyone in particular you confide in or talk to about yourself or your problems? '9 This question defines self-disclosure as the major component of a close relationship, and those respondents who confide in someone other than a spouse, child, or other relative were described as confiding in a friend. Whether or not this person was considered to be a friend was not addressed.

Respondents also have been asked simply to identify their closest friends and then to answer questions about each of them, leaving unspecified the criteria they have employed to decide whom to include. ${ }^{10}$ The assumption that all relationships identified in this way meet the same criteria and can be treated as essentially the same is probably unfounded, and Lowenthal and Robinson have concluded that 'different concepts of friendship perhaps may account for the inconsistent findings...' 11

By far the most common tactic employed in empirical research is a combination of imposing a definition and allowing the respondents to use their own. Research questions have focused on the amount and kind of social interaction between respondents and their friends and the effects of social interaction with friends on the morale of respondents. ${ }^{12}$ A necessary criterion, then, often has been that those identified be in close proximity (e.g. 'in this community') ${ }^{13}$ or seen regularly (e.g. 'whom you see most often') ${ }^{14}$ or both. This requirement stresses ongoing face-to-face interaction and makes ineligible friends with whom respondents are no longer in touch as well as those with whom relationships are maintained via infrequent visits, telephone conversations, letter writing, or mutual acquaintances. These friends, in fact, may be considered closer than those with whom they currently interact. Respondents in these studies, then, have been allowed to use their own unspecified definitions, but only within the confines set by the research questions. Drawing on findings from research using this type of definition to make general statements about friendship is to exceed the limits of these data, which can only contribute to an understanding of respondents' current, face-to-face relationships defined as friendships within the context of the research situation.

In all of these approaches to the study of friendship, the actual definitions employed by social actors have been ignored. Although the research reported here is similar to research that employs the tactic of allowing informants to use their own criteria to identify their friends, it departs from previous research by attempting to specify those definitions. Transcribed interviews with elderly social actors who were asked to discuss their friends while relating their biographies were analysed to delineate the definitions they employed in describing 
individuals as friends. Definitions of friendship were chosen as the focus of the presentation because they appeared to be an important key to understanding the informants' subjective evaluation of the quality of their relationships. Taking seriously W. I. Thomas' dictum that situations defined as real are real in their consequences, the analysis deals with both definitions and consequences. The questions addressed are first, a general one, what are the informants' definitions of friendship? and second, a more specific one, what consequences do these definitions have in old age? This analysis does not attempt to address the question of why informants held one definition rather than another. Before turning to these questions, the informants who provided the data analysed here, and the research design, will be described.

\section{Informants and research design}

In an attempt to include persons with diverse backgrounds, informants were recruited through several sources including a senior college programme $(n=\mathrm{I} 6)$; two retirement apartments, one medium to high income $(n=6)$ and one moderate income $(n=4)$; senior citizens programmes in both a low income area $(n=12)$ and a middle income area $(n=10)$; a community action agency $(n=5)$; and through acquaintances of the author $(n=7)$. Informants volunteered to participate after being told about the project by telephone or letter, or hearing a presentation made by the author or a research assistant. Prospective informants were presented with a brief description of the research project and asked to participate in a single interview which would last an hour-and-a-half to two hours, during which they would talk about friendship during the course of their lives. Informants, in some cases, were offered ten dollars for participating in the research. Most of the interviews took place in informants' homes, all between June 1980 and August i 981 .

The 60 informants, 30 men and 30 women, ranged in age from 60 to 89 (median age $=74$ ). All were living in independent housing situations at the time of the interview, 25 in their own homes, 18 in apartments, and $\mathrm{I} 7$ in apartments in retirement complexes. Slightly more than half $(n=32)$ were living alone, 2 I with spouses, three with spouses and a child or other relative, and four with a child, sibling, or friend. Of the 6o, 55 were white, 5 black. Fifteen of the informants were 'poor' throughout their lives, 3 I were 'comfortable', with the remainder being primarily upwardly mobile. Nine did not complete high school; I 5 were high school graduates; 8 had some college; and 25 had at least 
a college degree. (Data were missing for three.) Seven of the informants had never married. Of the 53 who had married, i 3 had been married more than once with I I having been divorced at some point in their lives. At the time of the interview, 24 were widowed or divorced.

The informants, then, are a diverse group. They were not intended to constitute a sample from which generalizations could be made to a population. Rather, in keeping with the exploratory nature of the research, they are a group in which the contents of biographies could be examined in relation to friendship in order to generate new and relevant issues and questions for future research on friendship.

Interviews were conducted as 'guided conversations', the object of which is 'to elicit from the interviewee what he considers to be important questions relative to a given topic, his descriptions of some situation being explored ${ }^{15}$ Informants were encouraged to relate their biographies while focusing both on the circumstances surrounding the formation, maintenance, and termination of specific friendships, and on perceptions of the more general meaning of friendship in their lives. The 'conversations' were tape-recorded. Transcripts were analysed ${ }^{16}$ to delineate, among other things, both the definitions of friendship and the consequences these definitions had in the informants' lives. Although each informant was asked specifically to define friendship, the data analysed here are primarily the definitions implicit in their discussions of their friendships, both current and past.

\section{Informants' definitions of friendship}

From a careful reading of the transcripts of the 60 interviews, two broad definitions of friendship emerged. The first one focuses on particular individuals who were considered to be friends, the second on the relationship per se. Obviously, all dyadic relationships require two individuals, in this case the informant and the identified friend. Using the first definition, however, only the specific persons could qualify as friends. In the latter, the focus was on the relationship rather than the person involved, so that the number of people who might qualify was greater. The underlying dimension here is replaceability. In the following discussion each category will be fleshed out in turn and the consequences that result from holding each in old age will be identified. 


\section{Friends as particular individuals}

What makes a particular person a friend was explained by one informant:

If you have the idea of a friendship as one in which you can share things more or less completely, how are you going to re-create whole sections of your own past for the purpose of an individual you have come to like very much, but who really has only known you since you were 50 years old?... You can say, 'Well, yes, when I was in Brazil', or 'When I drove a cab in New York City', and then you watch someone's eyes widen... You can't tell them. You can only skip over the high points.

This informant described someone he had known for almost thirty years as a 'close acquaintance' and did not feel that the person really knew him. At age 72, he considered his wife of fifty years to be his only friend, for she was the only person who knew the significance of the high- and low-points of his life. By the time old age is reached, in order to share things 'more or less completely', two people must have known one another over a major portion of their lives. Although they may not share each other's daily lives, they are part of one another's worlds even when they are not physically together.

One informant who met again after a long absence a friend from his youth explained, ' $I$ consider her probably my best friend at present. I could because there is such a link between my early life and present life which I don't share with most of the other so-called friends'. One informant was interviewed very shortly after the death of his 'best friend' whom he had known since college:

His death has just done a very bad job on my emotions. I feel very bad about it, because that's a real friend to have lasted over those many years, you know. We went to Florida last year to visit them, and he wanted us to move to Florida and we were seriously contemplating the possibility of moving to Florida, and now he's gone. So that narrows one's opportunities, closes gates.

The availability of a lifelong friend - a friend whose particular identity is important - is a precious asset, but also may make the old person vulnerable to a great sense of loss when the person dies.

Not all of the informants who had participated in this type of friendship had maintained one into old age. In some cases the friend had died. In others, the friend was reclassified so that she or he was no longer considered to be a friend. In still others, the informant had lost track of the person during the course of his or her life, but still considered the person to be a friend. This type of friendship, then, often was present only in memories, but served as a basis for comparison for the other 
definition of friendship. Friendships defined in terms of particular individuals were acquired early in life, at least by middle age, usually much earlier.

Particular friendships that had lasted into old age were not only lost to death, but also to the hardships that often accompany old age. Both decreased physical health and lack of monetary resources meant that the friends might never again be in each other's physical presence. For example, one woman said, 'My best friend was Carmen Jones whom I met in college and she's been my closest friend for years.' When she was employed, the informant had visited her friend in New York City whenever her profession took her there. However, she had recently concluded that travelling was no longer feasible for her and, very significantly for her, had skipped the fiftieth reunion of her college graduation class. She had ceased writing to her friend and introduced herself to the interviewer as someone who no longer had friends, even though her 'closest friend for years' was still alive.

Another informant who said that he had two friends responded to the query 'Has there ever been a time in your life when you felt that you had no friends?' with 'Right now'. One of his friends lived in New York and he saw him only once a year. About his friend in Los Angeles he said, 'I haven't seen him in years,' and concluded, 'I have no friends'. Declining physical capacity, incomes that will not cover travel expenses, and deaths, all spell the demise of these old friendships. Informants who were still able physically and financially to visit out-of-town friends made a point of doing so on a regular basis. Those who no longer were able, experienced a loss tantamount in many cases to the death of the friend.

\section{Friends as relationships}

One of the informants mentioned above described herself as friendless in part because she had resigned herself to never seeing her 'close friend' again, but also in part because of the absence of a friend in her daily life. To explain her dilemma to the interviewer, she cited two examples of people whom she considered to be friends who had abandoned her, one by moving to Arizona, the other by dying:

A friend is someone who responds to you and who you respond to whatever you are going through at the time. I was thinking of Madeline... When Kissinger was on the air, I would call her up and say, 'Look, Madeline, Kissinger is going to be on the air in five minutes', and she would say, 'Oh, I'm so glad you called me.' Then she would call me back afterward and we would talk. Or Mabel, when I called her up and said I couldn't get through 
to the hospital, I felt like I just had to tell someone. So then I called her the next day and told her all about it.

This informant called some months later to summarize the essence of what she had been saying: 'A friend is someone who attaches the same importance to something that you tell them that you do.' In the above instances, her animosity towards Kissinger and her concern about her daughter who was in the hospital were things the significance of which her friends understood. Her lament about her current situation was not absence of associates - she lived in a retirement hotel in which she socialized with others regularly - but absence of someone who understood what was important to her, in her words, 'Someone who knows about me'. It is not a particular person that she misses, but a person who supplies particular kinds of validation to herself. Replacing this type of friend may not always be easy, as this informant's pain indicates, but the chance is much greater than it is for the type of friend discussed first.

Informants who emphasized friendships as relationships were interested primarily in the presence of the person in their daily lives. One informant distinguished between her two closest friends: ' I know what Jane is doing every day, although I might not talk to her every day, but with Martha, I talk to her every day with little things that come up.' She considers the latter to be her best friend. Another informant explained, 'I would say that there is one person whose friendship I cherish and who I would go to if I needed what a friend can give you, but there have been other people that $I$ have felt just as close to as I do to this person.' In looking back over her life, she explained that, 'I just met people all along and I made many friends and had something doing all the time... Some of the depth of your friendship with people depends on how much you see people and how you're brought together...'

That the relationship is more important than the particular person who completes the dyad is illustrated by another informant who said, ' $M y$ best friends have moved away, so I have to substitute others and find some new ones. As you get older you have to have replacements all the time. You really do, because a lot of things happen to them.' Because she was single, the interviewer asked her questions about her relationships with married friends. Her response illustrates the flexibility of this definition:

I have friends who have married and who have husbands who will not tolerate their single friends... So then they meet me for lunch or for some of them their husbands die and then we get to be real good friends again... I never lose any of my friends. I keep them. I even have friends from grade school. 
For a friendship definition that focuses on the relationship rather than the person, availability is clearly an essential criterion.

\section{Friendship definitions as strategies}

Holding one or the other or both of the definitions of friendship discussed above has consequences in the lives of these elderly informants in that the 'naming of an object provides a directive for action', ${ }^{17}$ thereby prescribing certain expectations and behaviours and proscribing others. A specific definition or combination can be seen as a strategy for dealing with others to whom persons are not 'institutionally related '. ${ }^{18}$ It is strategic in that, irrespective of the consciousness of the actor, each definition or combination accomplishes a particular outcome, has an effect on the social actor's connectedness to others. Combining these two definitions of friendship leads to four different strategies, as shown in Table $\mathrm{I}$. Each of the strategies can be assessed with respect to its value for promoting older individuals' meaningful connectedness to ongoing social life. As will be seen below, some strategies are less able to accomplish this; are, in effect, more 'risky'.

Strategy 4 will be dealt with first because it can be disposed of quickly. None of the informants for this research fell into this category. Even informants who claimed to have no friends used one of these definitions to disqualify acquaintances. For example, one informant said, 'I got a lot of friends, too, but I don't say they're friends I would depend on... Do I have friends now? I have people that I know.' This man, then, used a 'friend as relationship' definition to disqualify those with whom he associated. However, whether or not there are individuals in the United States or other societies who subscribe to neither of these definitions is an empirical question that cannot be addressed with these data.

\section{Strategy 1 : particular individuals only}

Individuals who subscribe only to the definition 'friendship as particular persons' fall into this category, which is represented by the following informant's description of his current situation:

If my wife would go before me, I would certainly drop completely out of the scene here... Because with these people who live here, I... keep the semblance of friendship only because of my wife. These people have nothing to tell me, and I have nothing to say to them... If I did not see these people that we know here, not see them at all, ever, it wouldn't bother me a bit. I would sit home and listen to classical music and read a book. 
TAB LE I. Combinations of friendship definitions

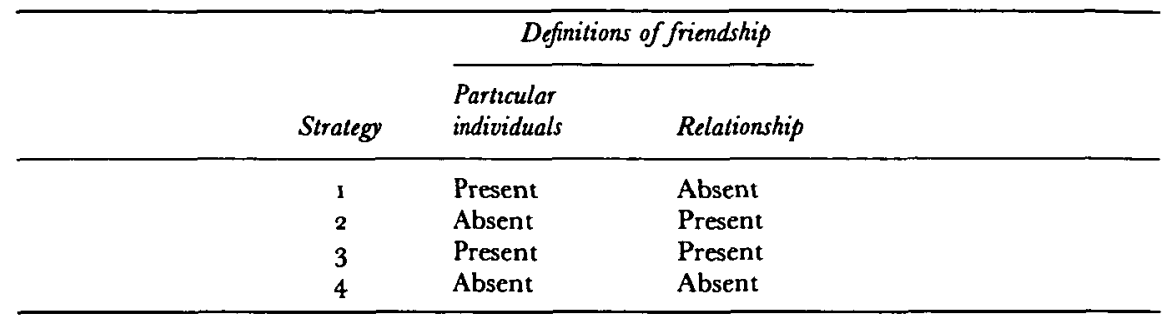

His few friends, however, he values a great deal but lives too far from them to visit often. Those people with whom he does associate he does not consider friends. Seven of the informants of this research appeared to use only this definition of friendship.

Of the three strategies, persons who use this one, all things being equal, have the fewest resources with which to buffer the effects of old age for two reasons. First, since none of their friends can be replaced, loss of those individuals will, to use Townsend's distinction, lead to loneliness, the underlying cause of which will be desolation rather than isolation. ${ }^{19}$ Marris' description of the loss felt by widows is parallel to the loss felt by informants who held only this definition of friendship: 'Feelings of loneliness seem to arise from the longing for a particular companion, rather than from lack of company.'20

The second reason that this is a risky strategy is that persons who adopt it are likely to have precarious social support networks. The informant used as an example above illustrates this. His link to a network is through his wife. Her death will remove the link, leaving him socially isolated. Most social scientists and clinicians agree that social isolation at any age is unhealthy, ${ }^{21}$ but isolation in old age, because of the decrements that are often its accompaniments, undermines the capacity to maintain independence. It is the old who use Strategy I - but not those who use Strategies 2 or 3 -about whom Rosow writes,

The person with only one confidant is in a tenuous equilibrium of dependence, functioning well so long as the intimate tie is intact, but vulnerable to its disruption. For a major emotional investment in a single relationship rather than a safter dispersal among several hampers flexibility and easy substitition for its loss. ${ }^{22}$

For the old who use only a 'particular individuals' definition of friendship there can be no substitution for the loss of a friend.

Of what use is this information to professionals who are concerned with promoting friendships among the aged who hold only this definition? An examination of the 'friendship as particular persons' 
definition revealed that in old age, at least, length of the friendship led to its irreplaceability, but what does leng th indicate? For the informants' explanations, it would seem to stand for the other member of the dyad's knowing all about him or her. It may be possible to create artificial situations that would promote sharing of biographies to the degree that persons would know all about one another. Life history classes like the ones arranged by Myerhoff to collect data for her book Number Our Days might benefit participants by allowing each to present his or her biography in a non-stigmatizing environment. ${ }^{23}$ Another alternative might be to promote reunions of former residents of areas of cities in which there has been a complete turnover in population. Meetings among people who 'knew each other when' might rekindle old friendships that would connect youth to old age. High school and college graduation class reunions may already be serving this function.

\section{Strategy 2: relationship only}

Some of the informants subscribed only to the definition 'friendships as relationships' and spoke only of the benefits of the relationship per se. Their investments were in the relationships, not in irreplaceable individuals. They were not cut off from others, however, so that those who used this definition exclusively were not socially isolated. For example, one informant said, ' $I$ had an interesting life, I think, and all along, you know, you make friends'. Twenty-five of the informants for this research appeared to use only this definition of friendship. It is possible, of course, that these informants, had they been interviewed earlier in their lives, would have used both definitions. In old age, however, they used only one.

Individuals who adopt Strategy 2 are less likely to be at risk. For those whose definitions focus on relationships, high concentrations of elderly persons with similar backgrounds are probably helpful. ${ }^{24}$ Some of the informants for the research were recruited through senior centres and a number of them used the daily lunch programmes to meet their friends. One informant explained, 'I've lost an awful lot of friends, friends that were pretty good friends when I was working... It seems like once I retired... they don't get in touch with me.' This man viewed the senior centres that he attended as the major source of his current friendships.

Similarly, one informant had moved into a retirement complex precisely because the apartment complex in which he and his wife had lived was unfriendly:

I never saw less friendly people in all my life. The type of people you would say good morning to and they'd walk right past. Wouldn't even answer 
you... And moving in here and seeing how human beings really live and react, it kind of restores your faith in mankind.

In the apartment complex, he had made it his business to promote the Men's Club and to recruit new members as men moved into the complex. This man had also depended for friends most of his life on the men he knew at work. To promote friendships among the old who define their friends in terms of relationships, ensuring that they meet others is an important first step. Although Kahn and Antonucci argue that 'People whose convoy relationships (networks of social support) remain role-linked are thus at greatest risk with increasing age, ${ }^{25}$ it is important to stress that some social actors are quite capable of creating the roles that link them to others. Individuals whose definitions of friendship are exclusively 'relationship' may, in fact, be very good at this.

\section{Strategy 3: particular individuals and relationships}

Individuals who subscribe to both definitions have particular friends whom they consider to be irreplaceable, ones they had acquired early in their lives, who in Hess's words represent 'previous investments of the self' ${ }^{26}$ At the same time, they had continued to acquire friends and to reap the benefits which were available in these relationships. Those friends, however, were and are replaceable. The informant cited above whose 'best friend' had recently died and 'done a job on his emotions', is, and has been, involved with others whom he considers to be friends. Their deaths he had not and will not take so hard. Subscribing to both definitions will not erase the pain of losing a particular friend, but it will probably make the pain more bearable. Almost half of the informants for this research appeared to use this strategy. These individuals will benefit from both types of interventions suggested above. At the same time, they are probably less likely to require interventions on their behalf.

\section{Implications}

The two definitions of friendship, 'friends as particular individuals' and 'friends as relationships', to which the old informants of this research subscribed, affect the options that are perceived by them to be available, and thus have consequences for the quality of their participation in social life. Persons who arrive in old age with only the definition of friendship as particular individuals reject any new acquaintance as a 
candidate for friend, while those who use 'friends as relationships' or both definitions are more open to the acquisition of friends in old age.

In a recent article by Jerrome, 49 of the 55 widowed and/or retired older women who informed her research adopted at least one of four strategies to 'compensate for the loss of close ties and the increase in leisure...'.

Some women extend and deepen existing relationships. Some grow closer to siblings and cousins. Some become full-time 'good neighbours' or assume responsibility for elderly relatives. Some acquire altogether new friends through voluntary associations and related social functions, or by moving into a new neighbourhood. ${ }^{27}$

The strategies adopted by these informants were, in all likelihood, dictated by their definitions of friendship. Acquiring 'altogether new friends through voluntary associations', for example, will not 'compensate' old persons who hold a 'particular individual' definition of friendship, while deepening existing relationships may. Whether or not courses of action can have the desired outcome, then, is dependent on the definitions to which individuals subscribe.

From the retrospective data collected, it appears that 'particular friends' were almost always acquired before age 40, usually much earlier. To still have an ongoing, supportive relationship with these individuals in old age is dependent on enough factors to attribute it in large part to fate. It is clear from the informants' descriptions that commitment is necessary, but by itself is not sufficient to preserve a friendship through the years. Co-operation of spouses, adequate incomes, geographical proximity, no other competing friendship, survival into old age, chance meetings, to name a few, seem to be contributing factors, ones which are often not in an individual's sphere of control. Informants who spoke of particular friends, then, were as likely to be speaking of friendships from the past as they were to be speaking of current friendships and, very significantly, to use both definitions. Those informants who had particular friends, but did not maintain those friendships throughout their lives, in most cases also used a definition of friendship that focused on relationship. In coping with the changes that occur with movement through the life course, this would appear to be an affective strategy with respect to continuing to be meaningfully connected to ongoing social life. Adding a 'relationship' definition to a 'particular individual' definition might be regarded as movement from one 'developmental stage' to another.$^{28}$ Clearly, maintaining only a definition of friendship as a particular individual into old age is a gamble in that connectedness is largely out of the person's control. 
Individuals who use the strategy based only on the definition of friends as relationships are perhaps the best adapted to living in modern societies. Persons who define friendship only in terms of particular individuals are vulnerable in that the forces that impinge on their relationships are many and difficult to control. Focusing only on relationships makes possible capitalizing on different kinds of situations, even those encountered in old age. Many would fault this strategy as being shallow, but a lifetime of actively adjusting close relationships to situations may be very good preparation, indeed, for the losses that are often the accompaniments of old age.

\section{NOTES}

I Rosow, I. Social Integration of the Aged. Free Press, New York, I967.

2 Chown, S. M. Friendship in old age. In Duck, S. and Gilmour, R. (eds.), Personal Relationships. 2. Developing Personal Relationships. Academic Press, New York, 1981, pp. 23 I.

3 Lowenthal, M. F. and Robinson, B. Social networks and isolaton. In Binstock, R. H. and Shanas, E. (eds.), Handbook of Aging and the Social Sciences. Van Nostrand Reinhold, New York, 1976.

4 Brown, B. B. A life-span approach to friendship: age-related dimensions of an ageless relationship. In Lopata, H. Z. and Maines, D. (eds.), Research in the Interweave of Social Roles. 2. Friendship. JAl Press, Greenwich, Connecticut, 1981, p. 25 .

5 Kurth, S. B. Friendship and friendly relations. In McCall, G. J. (ed.), Social Relationships. Aldine, Chicago, Illinois, 1970.

6 Reisman, J. M. Anatomy of Friendship. Irvington, New York, 1979, p. 209.

7 Allan, G. A. A Sociology of Friendship and Kinship. Allen and Unwin, Boston, 1979, p. 34 .

8 Bates, A. and Babchuk, N. The primary group: a re-appraisal, Sociological Quarterly, 2 (196I), 1 8I-19I ; Booth, A. and Hess, E. Cross-sex friendship, Journal of Marriage and the Family, $3^{6}$ (1974), 38-47. Booth and Hess, following Bates and Babchuk, define friendship as 'a primary relationship between two individuals unrelated by kinship. The term primary denotes (1) a predisposition to enter into a wide range of activities with one another; and (2) positive affect which is manifested in the mutual expression of concern, the repetition of private traditions, and the felt freedom to make demands on one other' (p. $3^{8}$ ). Although respondents were asked initially to identify their friends, the definition of friendship was imposed by the researchers.

9 Lowenthal, M. F. and Haven, C. Interaction and adaptation: intimacy as a critical variable. In Neugarten B. L. (ed.), Middle Age and Aging. University of Chicago Press, Chicago, Illinois, 1968.

Io Candy, S. E. G. A comparative analysis of friendship functions in six age groups of men and women. Doctoral dissertation, Department of Psychology, Wayne State University, Detroit, Michigan, 1977; Lopata, H. Z. Women as Widows. Elsevier, New York, 1979.

I I Lowenthal, M. F. and Robinson, B., op. cit.

12 Blau, Z. S. Structural constraints on friendship in old age, American Sociological Review, 26 (196r), 429-439; Lazarsfeld, P. F. and Merton, R. K. Friendship as social process: a substantive and methodological analysis. In Berger, M., Abel, R. 
and Page, C. H. (eds.), Freedom and Control in Modern Society. Van Nostrand, New York, 1954; Rosow, I., op. cit.; Verbrugge, L. M. The structure of adult friendship choices, Social Forces, 56 (1977), 576-597; Arling, G. The elderly widow and her family, neighbours, and friends, Journal of Marriage and the Family, $3^{8}$ (1976), 757-768; Bultena, G. The relationship of occupational status to friendship ties in three planned retirement communities, Joumal of Gerontology, 24 ( 1969$), 46 \mathrm{I}-464$; Fischer, C. S., Jackson, R. M., Steuve, K. G., McAllister-Jones, L. and Baldassare, M. Networks and Places: Social Relations in the Urban Setting. Free Press, New York, 1977; Petrowsky, M. Marital status, sex, and the social networks of the elderly, Joumal of Marriage and the Family, $3^{8}$ (1976), 749-756.

13 Arling, G., op. cit.; Phillips, D. L. Social class, social participation and happiness: a consideration of interaction opportunities and investment, Sociological Quarterly, 10 ( I 969), 3-2 I ; Rosow, I., op. cit.

14 Bultena, op. cit.

15 Lofland, J. Analyzing Social Settings: a Guide to Qualitative Observation and Analysis. Wadsworth, Belmont, California, ı97ı, p. 76 .

16 Ibid.

17 Strauss, A. Mirrors and Masks: the Search for Identity. Free Press, Glencoe, Illinois, 1959.

I8 Suttles, G. D. Friendship as a social institution. In McCall, G. J., op. cit.

19 Townsend, P. The Family Life of Old People. Routledge and Kegan Paul, London, 1957.

20 Marris, P. Widows and their Families. Routledge and Kegan Paul, London, 1958.

21 Weiss, R. S. Loneliness: the Experience of Emotional and Social Isolation, MIT Press, Cambridge, Massachusetts, 1974.

22 Rosow, I. Social psychology and gerontology: a discussion, International fournal of Aging and Human Development, 9 ( 1978 ), I 53-1 57.

23 Myerhoff, B. Number Our Days. E. P. Dutton, New York, 979.

24 Rosow, I., I967, op. cit.; Hochschild, A. R. The Unexpected Community. Berkeley, California: University of California Press, 1978.

$25 \mathrm{Kahn}, \mathrm{R}$. and Antonucci, T. Convoys of social support: a life-course approach. In Kiesler, S. B., Morgan, J. N. and Oppenheimer, V. K. (eds.). Aging: Social Change. Academic Press, New York, I 981 .

26 Hess, B. Friendship. In Riley, M. W., Johnson, M. and Foner, A. (eds.). Aging and Society. 3. A Sociology of Age Stratification. Russell Sage Foundation, New York, 1972.

27 Jerrome, D. The significance of friendship for women in later life, Ageing and Society, I (1981), 175-197.

28 Selman, R. L. The child as friendship philosopher. In Asher, S. R. and Gottman, J. M. (eds.). The Development of Children's Friendships. Cambridge University Press, New York, 1981 . 